\title{
Characterization of Class F Fly Ash Using STXM: Identifying Intraparticle Heterogeneity at Nanometer Scale
}

\author{
J. Ha, ${ }^{1}$ S. Chae, ${ }^{2}$ K. W. Chou, ${ }^{3,4}$ T. Tyliszczak, ${ }^{3}$ and P. J. M. Monteiro ${ }^{2}$ \\ ${ }^{1}$ School of Environmental and Sustainability Sciences, Kean University, Union, NJ 07083, USA \\ ${ }^{2}$ Department of Civil and Environmental Engineering, University of California-Berkeley, Berkeley, CA 94720, USA \\ ${ }^{3}$ Advanced Light Source, Lawrence Berkeley National Laboratory, Berkeley, CA 94720, USA \\ ${ }^{4}$ Henkel Ibérica S. A., Edificio Eureka, Campus UAB, Bellaterra, 08193 Barcelona, Spain \\ Correspondence should be addressed to J. Ha; haj@kean.edu
}

Received 13 October 2015; Accepted 25 February 2016

Academic Editor: Ping Xiao

Copyright (c) $2016 \mathrm{~J}$. Ha et al. This is an open access article distributed under the Creative Commons Attribution License, which permits unrestricted use, distribution, and reproduction in any medium, provided the original work is properly cited.

\begin{abstract}
Chemical and physical characterization of fly ash particles were conducted using scanning transmission X-ray microscopy (STXM). Compositional and spatial investigation and correlation among the main elemental constituents of fly ash $(\mathrm{Al}, \mathrm{Si}$, and $\mathrm{Fe}$ ) were conducted based on microscopic and NEXAFS spectral analysis. Homogeneous oxidation and coordination state of $\mathrm{Al}$ and Fe were observed whereas $\mathrm{Si}$ shows spatial variation in its chemical state. We also identified that $\mathrm{Si}$ and $\mathrm{Al}$ are spatially correlated at nanometer scale in which high concentration of $\mathrm{Si}$ and $\mathrm{Al}$ was concurrently and consistently observed within the $30 \mathrm{~nm}$ resolution whereas Fe distribution did not show any specific correlation to $\mathrm{Al}$ and Si. Results of this study indicate that fly ash chemical composition has heterogeneous distribution depending on the elements which would determine and result in the differences in the reactivity.
\end{abstract}

\section{Introduction}

The manufacturing process for Ordinary Portland Cement (OPC) emits a large amount of green-house gas, producing between 800 and $1000 \mathrm{~kg}$ of carbon dioxide per ton of OPC. In fact, the manufacturing of OPC is estimated to be responsible for around $8 \%$ of all carbon dioxide emissions worldwide [1]. Because of the chemical composition of fly ash, which contains quartz and amorphous silica, fly ash has emerged as a good substitute for the raw materials in cement production since fly ash can serve as pozzolan in producing cementitious materials [2]. In addition to its compositional advantage, the spherical shape as well as particle size distribution of fly ash further makes it a good construction material because of the low water demand and high particle packing $[3,4]$. Hence, in an effort to recycle the industrial waste byproducts and to reduce global $\mathrm{CO}_{2}$ production, numerous studies have been done on fly ash application to construction materials [5-8]. With the annual production of fly ash in the United States alone mounting to approximately 63 million tons per year from coal combustion in power plants, more opportunities are awaiting for using fly ash for different applications including cement production $[9,10]$. In particular, recent development and advancement in cement industry has identified that high-volume fly ash (HVFA) substituted materials (a.k.a. geopolymers or green cement) have potential to serve as useful and effective construction materials due to their durability and strengths without releasing carbon dioxide in the air during their manufacturing process [11, 12].

Despite the wide applications and increasing demands of recycling fly ash, relatively a small number of studies have been done on characterization of fly ash due to the inherent chemical and physical complexity of the materials. In the past, compositional heterogeneity has been identified as the spherical glass phase and the crystalline phase are simultaneously present in fly ash. Extensive X-ray diffraction (XRD) studies, compositional analysis such as X-ray fluorescence (XRF) measurements, and thermal analysis using thermogravimetric analyzer (TGA) were carried out to study correlation between the glassy phases and crystalline phases 
TABLE 1: Percent (\%) of elemental composition of Class F fly ash based on XRF analysis.

\begin{tabular}{lcccccccccc}
\hline wt. \% & $\mathrm{Na}_{2} \mathrm{O}$ & $\mathrm{MgO}$ & $\mathrm{Al}_{2} \mathrm{O}_{3}$ & $\mathrm{SiO}_{2}$ & $\mathrm{P}_{2} \mathrm{O}_{5}$ & $\mathrm{~K}_{2} \mathrm{O}$ & $\mathrm{CaO}$ & $\mathrm{TiO}$ & $\mathrm{MnO}_{2}$ & $\mathrm{Fe}_{2} \mathrm{O}_{3}$ \\
\hline Fly ash & 0.54 & 1.21 & 16.62 & 63.24 & 0.359 & 1.39 & 3.13 & 0.86 & 0.05 & 6.41 \\
\hline
\end{tabular}

in determining the reactivity of fly ash [13-18]. However, most of the studies to date on fly ash properties lack the sensitivity to probe the intrinsic heterogeneous nature of fly ash because they are done mostly on bulk materials. Conventional analytical techniques have limitations on providing structural and chemical details such as coexistence of different glassy phases in a single particle of fly ash. The spatial heterogeneity of the elemental composition on fly ash particles has been especially neglected due to the lack of proper experimental and analytical techniques.

However, it is important to identify the spatial correlation between the amorphous and crystalline phase as well as the elemental compositional correlation in fly ash particles at nanometer scale in order to identify the governing factor of determining the reactivity of fly ash. For example, when fly ash reacts with alkaline solution in cement production, surface chemistry of the fly ash determines the dissolution pathways which will then ultimately determine the following precipitation reaction pathways and reaction byproducts [1921]. It has been shown that the key parameter in determining the overall reactivity of fly ash has been the glass contents in the materials [22-25]. Having the amorphous glassy phase buried within the spherical morphological feature of the fly ash can possibly slow down the kinetics of the reactions compared to the ones with the amorphous phase exposed on the surface of the fly ash particles. It is also possible that fly ash with more iron atoms at the surface of particles has higher reactivity compared to the ones with more silicon atoms at the surface. Therefore, identifying the glass phases and the intercalated chemical states of the mixed phases is important in characterizing fly ash since the distribution and concentration of different phases ultimately control the reactivity of the materials and their applicability to construction materials.

Studies have suggested that most of the glassy constituents in fly ash are aluminosilicates but no further details with respect to the concomitant existence of glassy phases and the crystalline phases have been reported to date [26-28]. Current model for fly ash particles is expected to be the hollow particles with amorphous walls which frequently contain crystalline matter such as mullite while the glass phase itself may be homogeneous [29-33]. Despite the efforts and recent advances in experimental approaches by using a combination of vibrational spectroscopy, chemical separation methods, NMR, and XPS, challenges still remain in identifying the structure of fly ash particles [34-36].

In this study, we used a novel approach in characterizing fly ash particles by using synchrotron based scanning transmission X-ray microscopy (STXM) to investigate the spatial distribution of different elements and phases at nanometer scale. Two-dimensional map at spatial resolution of $30 \mathrm{~nm}$ was obtained by STXM to get the compositional and morphological information on fly ash particles while concurrent measurements of near edge X-ray absorption fine structure
(NEXAFS) provided chemical speciation of the samples. To our knowledge, this is the first work on characterizing fly ash particles using STXM work to resolve the current challenge in studying fly ash particles.

\section{Experimental Approach}

2.1. Materials and Sample Preparation. Class F fly ash particles are obtained from Bridger plant (Northern California) of Headwaters Resources. The American Society for Testing and Materials (ASTM) specifies two types of fly ash, Class $\mathrm{F}$ ash and Class $\mathrm{C}$ ash, for use as a pozzolan or mineral admixture in concrete. Class $\mathrm{F}$ ash is normally produced from burning anthracite or bituminous coal. Samples of Class F fly ash from combustion of bituminous coal at electric power plants were examined in this study. XRF analysis was conducted at University of California at Berkeley, XRF Laboratory, to identify the chemical composition using Phillips PW2400 X-ray fluorescence (XRF) spectrometer. The major and minor element compositions are given in Table 1. The sample contains $\mathrm{Si}, \mathrm{Al}$, and $\mathrm{Fe}$ as the major constituents with approximately $63 \% \mathrm{Si}, 17 \% \mathrm{Al}$, and $6 \% \mathrm{Fe}$. The $\mathrm{Ca}$ concentration was approximately $3 \%$. XRD analysis indicates that hematite $\left(\alpha-\mathrm{Fe}_{2} \mathrm{O}_{3}\right)$, mullite $\left(\mathrm{Al}_{2}\left[\mathrm{Al}_{2+2 x} \mathrm{Si}_{2-2 x}\right] \mathrm{O}_{10-2 x}\right)$, and quartz $\left(\mathrm{SiO}_{2}\right)$ are the main crystalline phases occurring in the bulk samples of Class F fly ash.

For STXM measurements, samples were studied in polished cross section in order to examine the internal structure and composition of individual particles. A representative portion of fly ash sample was impregnated with epoxy, allowed to harden, and then polished using ion milling techniques. Sample was characterized by randomly selecting 3-4 fields of view and examining all the fly ash particles observed within the selected fields to obtain a statistical representation of the sample.

2.2. STXM Measurements. STXM is a transmission microscopy using a monochromated X-ray beam produced by synchrotron radiation. X-ray absorption edges occur when an incident photon energy exceeds the binding energy needed to remove an electron completely from an orbital shell. Different near edge absorption bands are observed depending on the absorbing atoms and these bands are sensitive indicators of the local chemical bonding environment surrounding the atom of interest. In addition to obtaining the chemical speciation information, STXM allows identifying heterogeneity within the samples on a particle-by-particle basis. Using the scanning transmission X-ray microscopy (STXM) together with concurrent measurements of near edge X-ray absorption fine structure (NEXAFS) spectra, it is possible to examine sample compositions and spatial heterogeneities.

Two different types of results were collected at the STXM beamline. First, image contrast data is obtained from 

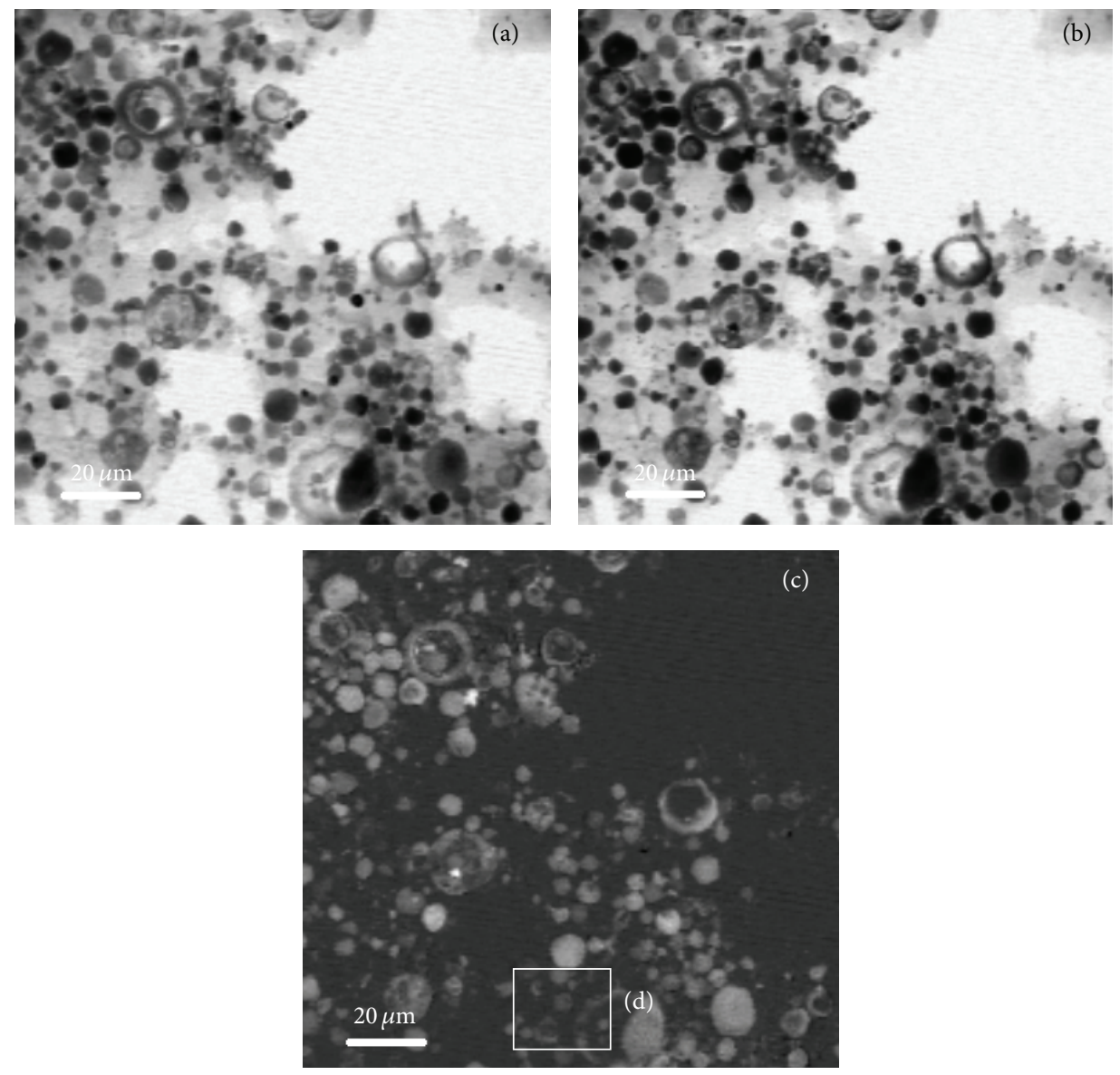

FIgURE 1: STXM images of Class F fly ash for Al K-edge taken at (a) $1550 \mathrm{eV}$; (b) $1570 \mathrm{eV}$; (c) image map of samples by taking a contrast between (a) and (b); (d) image map of the smaller area shown as a white rectangular region in (c) for spectral analysis.

differential absorption of X-rays depending on the chemical composition of the sample. Second, image stacks or line scan data are obtained by scanning the sample in the $x-y$ direction (image stack) energy increments of $0.1 \mathrm{eV}$ over the energy range of interest. Normalization and background subtraction of the spectra were performed by dividing each spectrum from the sample by the spectrum of the sample-free location. Elemental maps of the samples can be obtained by subtracting the image obtained from below the absorption energy level and the image obtained above the absorption energy. Axis 2000 software (version 2.1) [37] was used to align image stacks and extract NEXAFS spectra from image stack or line scan measurements. In this study, the STXM results were collected at the Advanced Light Source (ALS) branch lines 11.0.2.2. and 5.3.2. with the synchrotron storage ring operating at $1.9 \mathrm{GeV}$ and $200-400 \mathrm{~mA}$ stored current. More details on experimental approach and data analysis can be found in previous STXM work on cement samples [38, 39].

\section{Results and Discussions}

Figure 1 shows STXM image of Class F fly ash particles at below and above $\mathrm{Al} \mathrm{K}$-edge. As described in the experimental section, image contrast measurements, a.k.a. image mapping, identify a concentrated area of the element of interest by taking the pixel intensity before the absorption edge of the element and subtracting it from the same image taken above the absorption edge. Figure 1(a) is the area of clustered fly ash particles taken at $1555 \mathrm{eV}$, which is below the absorption edge of $\mathrm{Al}$. This image is subtracted from image of the same location taken above the $\mathrm{Al}$ absorption edge $(1570 \mathrm{eV})$ as shown in Figure 1(b). The final results, that is, image mapping, are shown in Figure 1(c) where the high concentrated $\mathrm{Al}$ area is identified as bright white locations. Once it was confirmed that there was element of interest, then a smaller area of the image is selected and magnified to observe fine features of samples and to measure NEXAFS spectra from various locations to identify possible heterogeneity in chemical species within the samples at spatial resolution up to $25 \sim 30 \mathrm{~nm}$. $10 \mu \mathrm{m} \times 10 \mu \mathrm{m}$ of smaller region was chosen for detailed investigation shown as a small rectangular region in Figure 1(c).

Al K-edge NEXAFS spectra are taken from various locations within the single particle of fly ash as shown in Figure 2(a). As shown in Figure 2(b), no significant changes in the peak positions and features in the $\mathrm{Al} \mathrm{K}$ edge spectra were observed suggesting that no changes in oxidation state or coordination environments occur with 


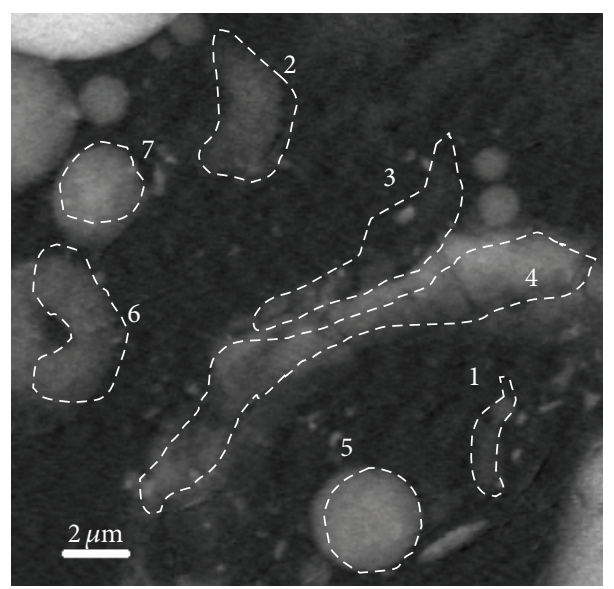

(a)

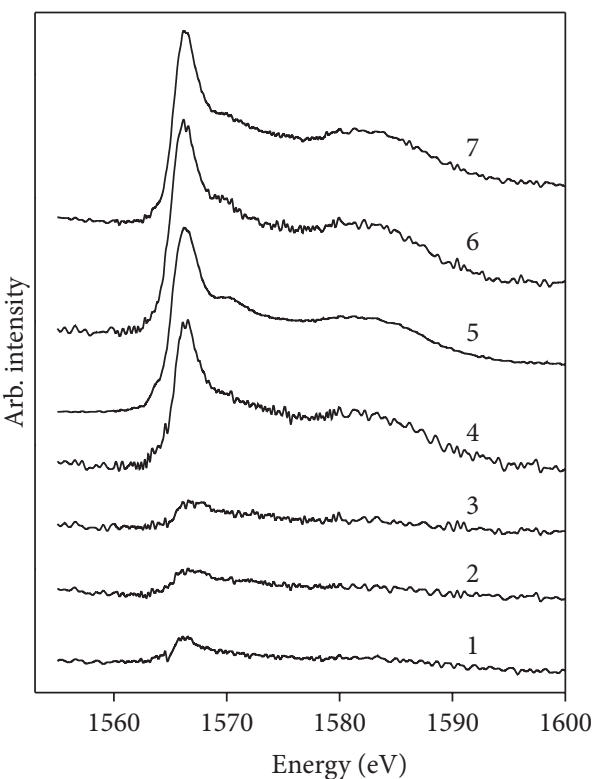

(b)

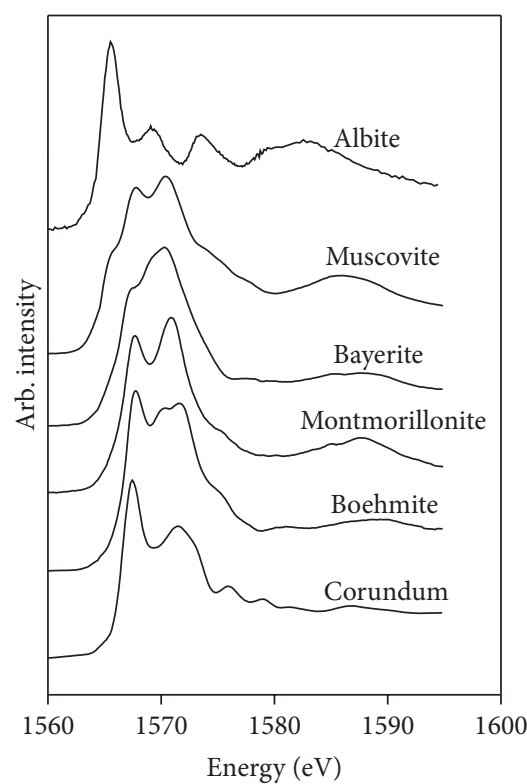

(c)

FIgURE 2: (a) STXM image map of Class F fly ash for Al K-edge. Numbers indicate the corresponding spectra from which the NEXAFS Al K-edge spectra are taken within the dotted enclosed region; (b) NEXAFS Al K-edge spectra of sample; (c) NEXAFS Al K-edge spectra of reference compounds.

respect to $\mathrm{Al}$ atoms in this sample. Concentration variation was observed since areas with relatively less $\mathrm{Al}$ contents were found within the $\mathrm{nm}$ range of the spatial resolution (see spectra 1-3 in Figure 2(b)). Studies have shown that a clear distinction can be made between the XANES spectra of tetrahedrally coordinated $\mathrm{Al}$ and octahedrally coordinated Al. Absorption band occurring at $1566 \mathrm{eV}$ is characteristic of tetrahedral compounds whereas peaks at 1568 and $1572 \mathrm{eV}$ are characteristic of octahedral compounds [40]. Comparing the sample spectra to the reference Al containing mineral spectra as shown in Figure 2(c), we conclude that the single peak at $1566 \mathrm{eV}$ in our fly ash sample is due to the tetrahedrally coordinated Al. Our sample spectra are similar to previously reported Al K-edge NEXAFS spectra of mordenite-type aluminosilicate containing $\mathrm{Al}$ atoms in the zeolite framework or mullite [41]. Based on our STXM and NEXAFS analysis, we conclude that only tetrahedrally coordinated $\mathrm{Al}$ is present and its concentration varies within a single particle of fly ash. Other studies have also identified tetrahedrally coordinated $\mathrm{Al}$ in cementitious materials using various other experimental approaches [42, 43], but our work is the first of the kind in suggesting the special heterogeneity of the $\mathrm{Al}$ coordination in fly ash sample.

Figures 3(a) and 3(b) show Fe $\mathrm{L}_{\mathrm{II}, \mathrm{III}}$-edge and Si K-edge image maps of the same sample site as $\mathrm{Al} \mathrm{K}$-edge image map was taken. We observed spatial heterogeneity with different elements by comparing the image maps of all three different elements. For example, areas 4, 5, 6, and 7 have relatively high concentration of both $\mathrm{Si}$ and Al based on the NEXAFS spectral analysis. Areas 1, 2, and 3 all contain relatively low 


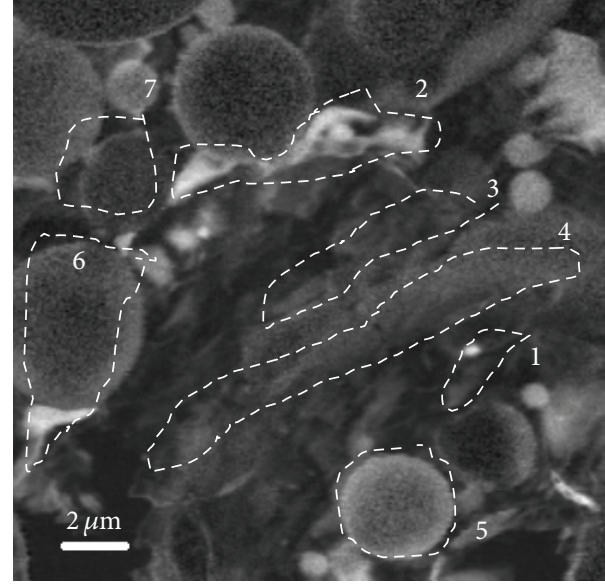

(a)

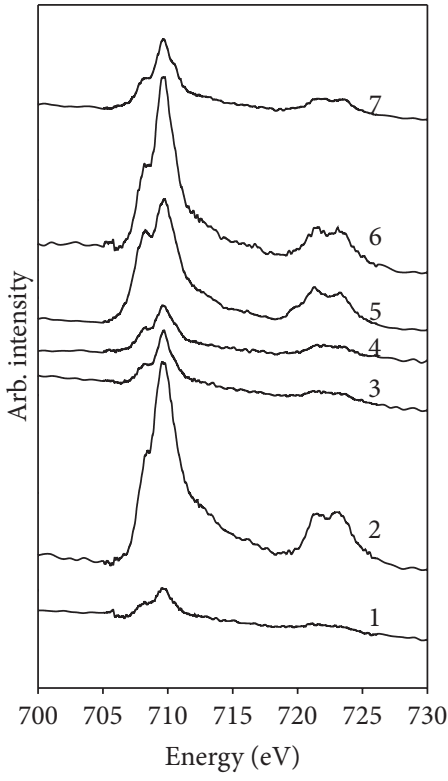

(c)

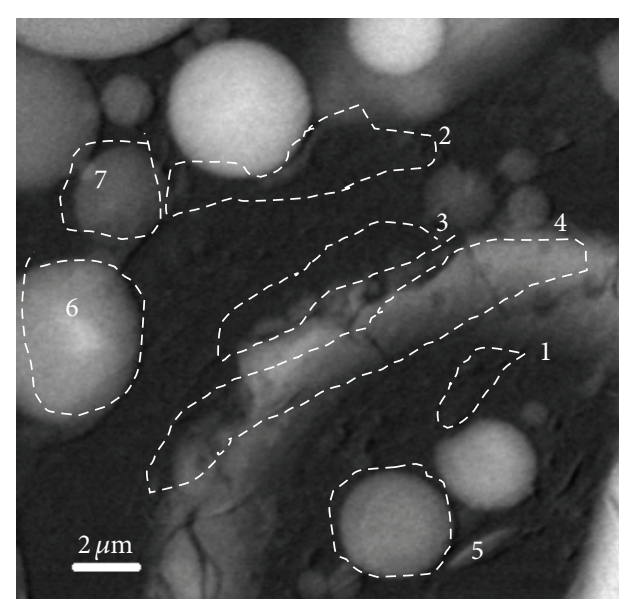

(b)

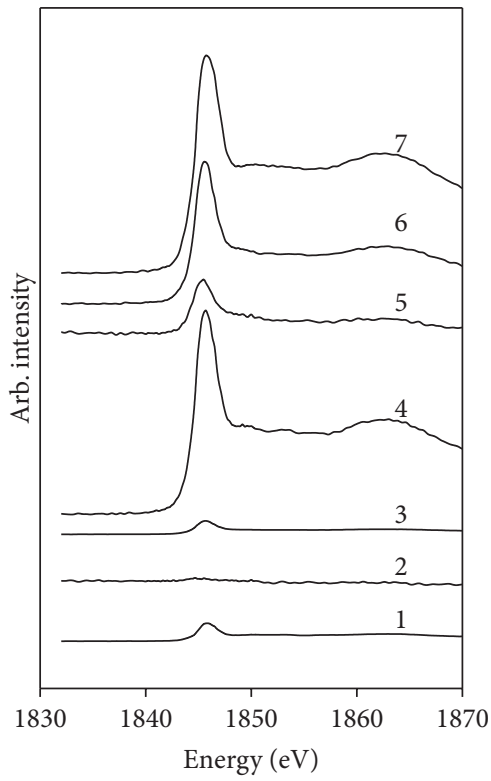

(d)

Figure 3: STXM image map of Class F fly ash at (a) Fe $\mathrm{L}_{\mathrm{II}, \mathrm{III}}$-edge; (b) Si K-edge. NEXAFS spectra of sample taken from various regions as shown in the image map for (c) Fe $\mathrm{L}_{\mathrm{II}, \mathrm{III}}$-edge; (d) Si K-edge.

concentration of both $\mathrm{Si}$ and $\mathrm{Al}$. This confirms that there is fairly strong chemical correlation between Si and Al. STXM also confirms that spatial variation in terms of elemental concentration exists within the fly ash particles. On the other hand, Fe concentration and spatial distribution did not have strong correlation with Si nor Al. For example, relatively low concentration of both $\mathrm{Si}$ and $\mathrm{Al}$ was found in area 2 whereas high concentration of $\mathrm{Fe}$ was found in area 2. Area 7 was found to contain high concentration of Si and Al, yet it had relatively low amount of $\mathrm{Fe}$. We cannot conclude that there is an inverse correlation either since area 6 contains relatively high concentration for all three elements. We would like to note that this conclusion is based on examination of at least three different sites on different particle samples to enhance our statistical confidence in conclusion.
Based on the spectral features and their comparison to previous Fe $\mathrm{L}_{\mathrm{II}, \mathrm{III}}$-edge NEXAFS spectra, we conclude that it is dominantly oxidized $\mathrm{Fe}$ (i.e., $\mathrm{Fe}^{3+}$ ) in the fly ash sample as shown in Figure 3(c). Unlike $\mathrm{Al}$ and Fe, Si K-edge NEXAFS spectra showed spatial variations as shown in Figure 3(d). For example, spectrum taken from area 4 has its major peak at $1846.8 \mathrm{eV}$ whereas the one from area 7 has its peak at $1858.3 \mathrm{eV}$. Previous work has demonstrated that Si K-edge NEXAFS spectrum can serve as fingerprints of local structural variations in silicate. For example, a four-oxygen coordinated $\mathrm{Si}$, such as in quartz, has a Si K-edge absorption edge at around $1846.8 \mathrm{eV}$ whereas six-oxygen coordinated $\mathrm{Si}$, such as in stishovite, has its absorption edge at around $1858.3 \mathrm{eV}$ [44]. Hence, we conclude that Si has intra- and interparticle spatial variation with respect to its coordination environment. 


\section{Conclusions}

In summary, we have observed homogeneous oxidation and coordination state of $\mathrm{Al}$ as shown in $\mathrm{Al}$ K-edge NEXAFS spectra with heterogeneity in its spatial distribution. We also identified that $\mathrm{Si}$ and $\mathrm{Al}$ are spatially correlated at nanometer scale in which high concentrations of $\mathrm{Si}$ and $\mathrm{Al}$ were concurrently and consistently observed within the $30 \mathrm{~nm}$ resolution. However, Fe distribution did not show any specific correlation to $\mathrm{Al}$ and $\mathrm{Si}$ and mostly oxidized form of Fe based on $\mathrm{Fe} \mathrm{L}_{\mathrm{II}, \mathrm{III}}$-edge NEXAFS spectra. Unlike $\mathrm{Al}$ and $\mathrm{Fe}$ where no variation in chemical oxidation and coordination was observed, Si showed spatial inter- and intraparticle variations in polymerization. Our work suggests that spatial heterogeneous distribution of elements exists in the fly ash sample. Future work on examining the overall reactivity of the fly ash and relating it to nanometer range elemental distribution and chemical compositions will further enhance our understanding of fly ash.

\section{Competing Interests}

The authors declare that there are no competing interests regarding the publication of this paper.

\section{Acknowledgments}

This research is funded by the Republic of Singapore's National Research Foundation through a grant to the Berkeley Education Alliance for Research in Singapore (BEARS) for the Singapore-Berkeley Building Efficiency and Sustainability in the Tropics (SinBerBEST) Program. The authors also wish to acknowledge Professor Wenk at University of California at Berkeley who helped them prepare STXM samples and Timothy Teague at University of California at Berkeley with his help on sample preparation. The Advanced Light Source is supported by the Director, Office of Science, Office of Basic Energy Sciences, of the US Department of Energy under Contract no. DE-AC02-05CH11231.

\section{References}

[1] D. J. M. Flower and J. G. Sanjayan, "Green house gas emissions due to concrete manufacture," International Journal of Life Cycle Assessment, vol. 12, no. 5, pp. 282-288, 2007.

[2] S.-H. Han, J.-K. Kim, and Y.-D. Park, "Prediction of compressive strength of fly ash concrete by new apparent activation energy function," Cement and Concrete Research, vol. 33, no. 7, pp. 965971, 2003.

[3] K. H. Abel and L. A. Rancitelli, "Major, minor, and trace element composition of coal and fly ash, as determined by instrumental neutron activation analysis," in Trace Elements in Fuel, S. P. Babu, Ed., vol. 141 of Advances in Chemistry, chapter 10, pp. 118138, American Chemical Society, 1975.

[4] J. L. Provis, V. Rose, S. A. B. And, and J. S. J. V. Deventer, "Highresolution Nanoprobe X-ray fluorescence characterization of heterogeneous calcium and heavy metal distributions in alkaliactivated fly ash," Langmuir, vol. 25, no. 19, pp. 11897-11904, 2009.
[5] D. S. Apul, K. H. Gardner, T. T. Eighmy, A.-M. Fällman, and R. N. J. Comans, "Simultaneous application of dissolution/precipitation and surface complexation/surface precipitation modeling to contaminant leaching," Environmental Science \& Technology, vol. 39, no. 15, pp. 5736-5741, 2005.

[6] T. Cobb James, C. P. Mangelsdorf, R. Blachere Jean et al., "Highstrength Portland cement concrete containing municipal solid waste incinerator ash," in Clean Energy from Waste and Coal, vol. 515, pp. 264-275, American Chemical Society, 1992.

[7] J. L. Provis, G. C. Lukey, and J. S. J. van Deventer, "Do geopolymers actually contain nanocrystalline zeolites? A reexamination of existing results," Chemistry of Materials, vol. 17, no. 12, pp. 3075-3085, 2005.

[8] Sindhunata, J. L. Provis, G. C. Lukey, H. Xu, and J. S. J. van Deventer, "Structural evolution of fly ash based geopolymers in alkaline environments," Industrial \& Engineering Chemistry Research, vol. 47, no. 9, pp. 2991-2999, 2008.

[9] M. H. Piispanen, S. A. Arvilommi, B. Van Den Broeck et al., "A comparative study of fly ash characterization by LA-ICP-MS and SEM-EDS," Energy \& Fuels, vol. 23, no. 7, pp. 3451-3456, 2009.

[10] M. J. McCarthy, L. J. Csetenyi, A. Sachdeva, and R. K. Dhir, "Identifying the role of fly ash properties for minimizing sulfateheave in lime-stabilized soils," Fuel, vol. 92, no. 1, pp. 27-36, 2012.

[11] F. P. Glasser, J. Marchand, and E. Samson, "Durability of concrete-degradation phenomena involving detrimental chemical reactions," Cement and Concrete Research, vol. 38, no. 2, pp. 226-246, 2008.

[12] V. M. Malhotra, "Durability of concrete incorporating highvolume of low-calcium (ASTM Class F) fly ash," Cement and Concrete Composites, vol. 12, no. 4, pp. 271-277, 1990.

[13] C. H. Fu, W. Ni, H. Wu, and M. Y. Tian, "Strength and microstructural characteristics of slag-fly ash based cementitious materials," Environmental Engineering and Management Journal, vol. 10, no. 7, pp. 951-954, 2011.

[14] S. P. Guleria and R. K. Dutta, "Unconfined compressive strength of fly ash-lime-gypsum composite mixed with treated tire chips," Journal of Materials in Civil Engineering, vol. 23, no. 8, pp. 1255-1263, 2011.

[15] S. Zahi and A. R. Daud, "Fly ash characterization and application in Al-based Mg alloys," Materials \& Design, vol. 32, no. 3, pp. 1337-1346, 2011.

[16] P. Adamiec, J.-C. Benezet, and A. Benhassaine, "Pozzolanic reactivity of silico-aluminous fly ash," Particuology, vol. 6, no. 2, pp. 93-98, 2008.

[17] M. Back, M. Kuehn, H. Stanjek, and S. Peiffer, "Reactivity of alkaline lignite fly ashes towards $\mathrm{CO}_{2}$ in water," Environmental Science \& Technology, vol. 42, no. 12, pp. 4520-4526, 2008.

[18] J. Zhang, C. F. You, S. W. Zhao, C. H. Chen, and H. Y. Qi, "Characteristics and reactivity of rapidly hydrated sorbent for semidry flue gas desulfurization," Environmental Science \& Technology, vol. 42, no. 5, pp. 1705-1710, 2008.

[19] S. Kumar, R. Kumar, T. C. Alex, A. Bandopadhyay, and S. P. Mehrotra, "Influence of reactivity of fly ash on geopolymerisation," Advances in Applied Ceramics, vol. 106, no. 3, pp. 120-127, 2007.

[20] J. G. S. van Jaarsveld, J. S. J. van Deventer, and G. C. Lukey, "The characterisation of source materials in fly ash-based geopolymers," Materials Letters, vol. 57, no. 7, pp. 1272-1280, 2003. 
[21] C. Li, Y. Li, H. H. Sun, and L. T. Li, “The composition of fly ash glass phase and its dissolution properties applying to geopolymeric materials," Journal of the American Ceramic Society, vol. 94, no. 6, pp. 1773-1778, 2011.

[22] C. Shi, Y. Wu, C. Riefler, and H. Wang, "Characteristics and pozzolanic reactivity of glass powders," Cement and Concrete Research, vol. 35, no. 5, pp. 987-993, 2005.

[23] C. Shi and R. L. Day, "Acceleration of the reactivity of fly ash by chemical activation," Cement and Concrete Research, vol. 25, no. 1, pp. 15-21, 1995.

[24] N. W. Chen-Tan, A. Van Riessen, C. V. Ly, and D. C. Southam, "Determining the reactivity of a fly ash for production of geopolymer," Journal of the American Ceramic Society, vol. 92, no. 4, pp. 881-887, 2009.

[25] G. L. Valenti, R. Cioffi, L. Santoro, and S. Ranchetti, "Influence of chemical and physical properties of Italian fly ashes on reactivity towards lime, phosphogypsum and water," Cement and Concrete Research, vol. 18, no. 1, pp. 91-102, 1988.

[26] L. D. Hulett and A. J. Weinberger, "Some etching studies of the microstructure and composition of large aluminosilicate particles in fly ash from coal-burning power plants," Environmental Science \& Technology, vol. 14, no. 8, pp. 965-970, 1980.

[27] T. Bakharev, "Geopolymeric materials prepared using Class F fly ash and elevated temperature curing," Cement and Concrete Research, vol. 35, no. 6, pp. 1224-1232, 2005.

[28] A. Fernández-Jiménez, A. Palomo, and M. Criado, "Microstructure development of alkali-activated fly ash cement: a descriptive model," Cement and Concrete Research, vol. 35, no. 6, pp. 1204-1209, 2005.

[29] L. D. Hansen, D. Silberman, and G. L. Fisher, "Crystalline components of stack-collected, size-fractionated coal fly ash," Environmental Science \& Technology, vol. 15, no. 9, pp. 10571062, 1981.

[30] G. L. Fisher, D. P. Y. Chang, and M. Brummer, "Fly ash collected from electrostatic precipitators: microcrystalline structures and the mystery of the spheres," Science, vol. 192, no. 4239, pp. 553$555,1976$.

[31] B. G. Kutchko and A. G. Kim, "Fly ash characterization by SEMEDS," Fuel, vol. 85, no. 17-18, pp. 2537-2544, 2006.

[32] L. D. Hulett, A. J. Weinberger, K. J. Northcutt, and M. Ferguson, "Chemical species in fly ash from coal-burning power plants," Science, vol. 210, no. 4476, pp. 1356-1358, 1980.

[33] J. S. Jung, H. C. Park, and R. Stevens, "Mullite ceramics derived from coal fly ash," Journal of Materials Science Letters, vol. 20, no. 12, pp. 1089-1091, 2001.

[34] N. Shigemoto, S. Sugiyama, H. Hayashi, and K. Miyaura, "Characterization of Na-X, Na-A, and coal fly ash zeolites and their amorphous precursors by IR, MAS NMR and XPS," Journal of Materials Science, vol. 30, no. 22, pp. 5777-5783, 1995.

[35] S. Gomes and M. François, "Characterization of mullite in silicoaluminous fly ash by XRD, TEM, and 29Si MAS NMR," Cement and Concrete Research, vol. 30, no. 2, pp. 175-181, 2000.

[36] M. Y. A. Mollah, T. R. Hess, and D. L. Cocke, "Surface and bulk studies of leached and unleached fly ash using XPS, SEM, EDS and FTIR techniques," Cement and Concrete Research, vol. 24, no. 1, pp. 109-118, 1994.

[37] A. P. Hitchcock, aXis2000, http://unicorn.mcmaster.ca/aXis2000 .html.

[38] S. R. Chae, J. Moon, S. Yoon et al., "Advanced nanoscale characterization of cement based materials using X-ray synchrotron radiation: a review," International Journal of Concrete Structures and Materials, vol. 7, no. 2, pp. 95-110, 2013.
[39] P. J. M. Monteiro, L. Clodic, F. Battocchio et al., "Incorporating carbon sequestration materials in civil infrastructure: a micro and nano-structural analysis," Cement and Concrete Composites, vol. 40, pp. 14-20, 2013.

[40] L. A. Bugaev, J. A. Van Bokhoven, V. V. Khrapko, L. A. Avakyan, and J. V. Latokha, "Effect of aluminum on the local structure of silicon in zeolites as studied by Si K edge X-ray absorption nearedge fine structure: spectra simulation with a non-muffin tin atomic background," The Journal of Physical Chemistry B, vol. 113, no. 14, pp. 4614-4618, 2009.

[41] J. A. van Bokhoven, H. Sambe, D. E. Ramaker, and D. C. Koningsberger, "Al K-edge near-edge X-ray absorption fine structure (NEXAFS) study on the coordination structure of aluminum in minerals and Y zeolites," The Journal of Physical Chemistry B, vol. 103, no. 36, pp. 7557-7564, 1999.

[42] A. N. Christensen, T. R. Jensen, and J. C. Hanson, "Formation of ettringite, $\mathrm{Ca}_{6} \mathrm{Al}_{2}\left(\mathrm{SO}_{4}\right)_{3}(\mathrm{OH})_{12} \cdot 26 \mathrm{H}_{2} \mathrm{O}$, AFt, and monosulfate, $\mathrm{Ca}_{4} \mathrm{Al}_{2} \mathrm{O}_{6}\left(\mathrm{SO}_{4}\right) \cdot 14 \mathrm{H}_{2} \mathrm{O}$, AFm-14, in hydrothermal hydration of Portland cement and of calcium aluminum oxide-calcium sulfate dihydrate mixtures studied by in situ synchrotron X-ray powder diffraction," Journal of Solid State Chemistry, vol. 177, no. 6, pp. 1944-1951, 2004.

[43] A. Rai, D. Lee, K. Park, and M. R. Zachariah, "Importance of phase change of aluminum in oxidation of aluminum nanoparticles," The Journal of Physical Chemistry B, vol. 108, no. 39, pp. 14793-14795, 2004.

[44] A. M. Flank, N. Trcera, F. Brunet, J.-P. Itié, T. Irifune, and P. Lagarde, "Experimental evidence of six-fold oxygen coordination for phosphorus and XANES calculations," Journal of Physics: Conference Series, vol. 190, no. 1, Article ID 012174, 2009. 

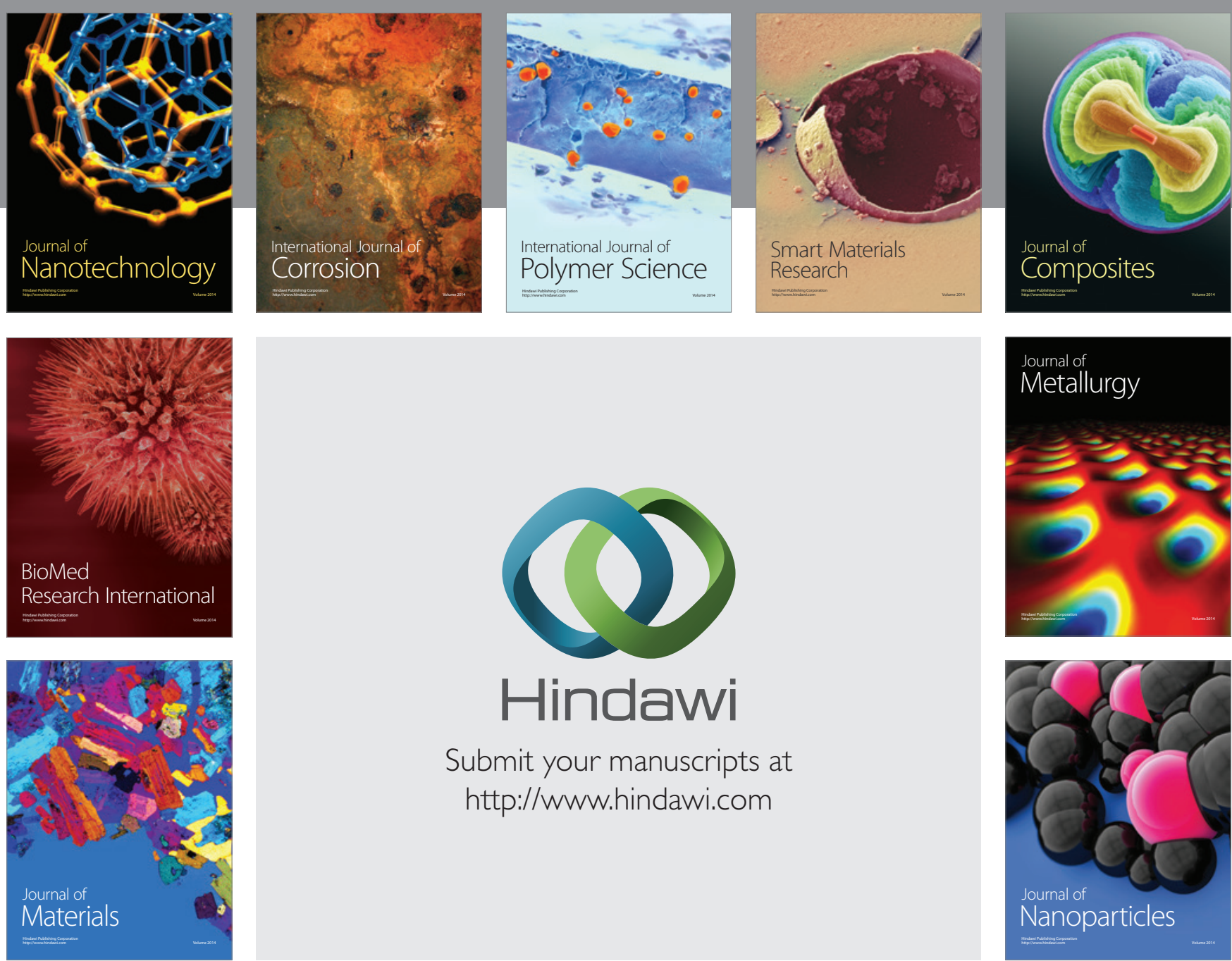

\section{Hindawi}

Submit your manuscripts at

http://www.hindawi.com

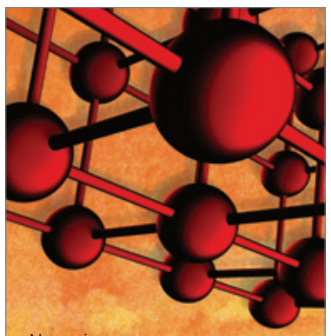

Materials Science and Engineering
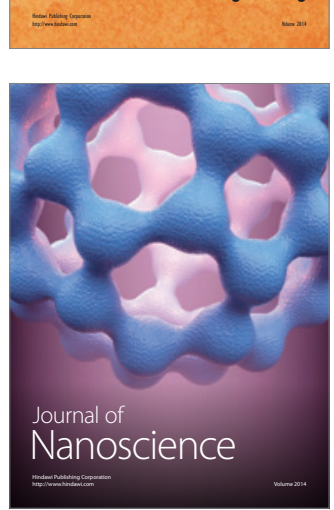
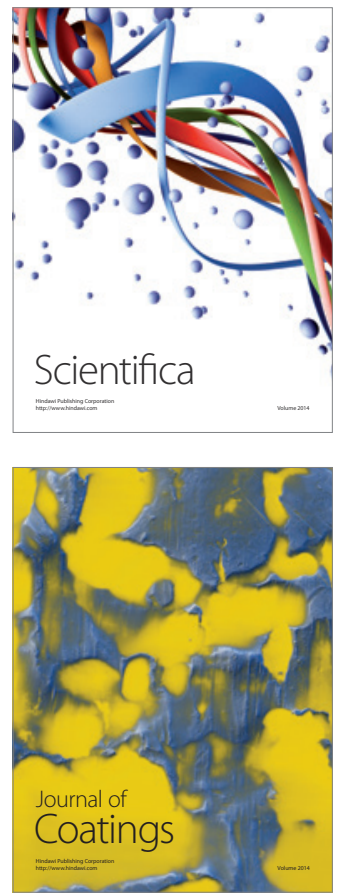
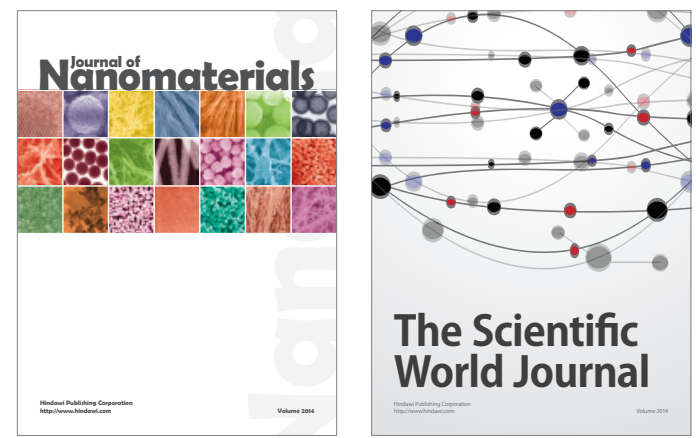

The Scientific World Journal
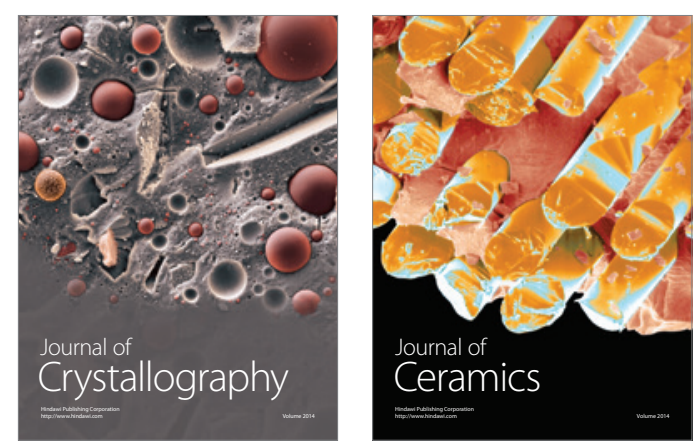
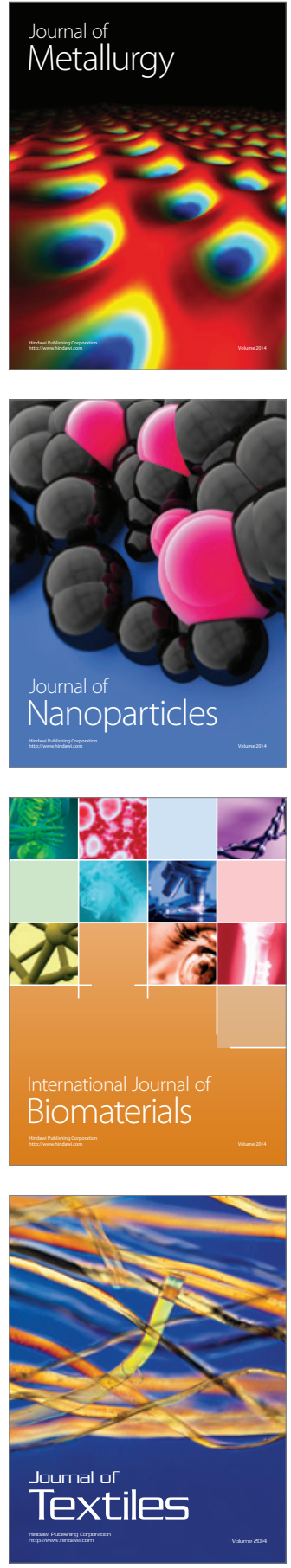